\title{
Influence of gender on prevalence of overweight and obesity in Nigerian schoolchildren and adolescents
}

\author{
FATAI A. MARUF ${ }^{*}$, UZOCHUKWU ARONU', KENNETH CHUKWUEGBU' and ANN E. ARONU ${ }^{2}$ \\ ${ }^{1}$ Department of Medical Rehabilitation, College of Health Sciences and Technology, Nnamdi Azikiwe University, \\ Nnewi Campus, Nnewi, Anambra State, Nigeria \\ ${ }^{2}$ Department of Paediatrics, University of Nigeria Teaching Hospital, Enugu, Nigeria
}

\begin{abstract}
Overweight and obesity are serious health concerns for children. However, only a few studies have investigated the influence of gender on prevalence of overweight and obesity in children and adolescents in Nigeria. The objective of this study was to investigate gender influence on prevalence of overweight and obesity among Nigerian school children and adolescents. Information on age and gender of the participants was collected from the school register. Data on height, weight and BMI was collected using standard techniques. A total of 9,014 children and adolescents (male=4392; female=4622), aged 2-18 years, from 28 randomly selected schools were analyzed. Overweight and obesity were determined using the International Obesity Task Force cut-off points by age and gender. Males had higher BMI than females at age group 2-6 years, whereas females had higher BMI than males at age groups 11-14 years and 15-18 years. Females had significantly higher prevalence of overweight $(P<0.05)$ than males at age group 11-14 and 15-18 years. However, there was no gender difference in the prevalence of obesity from childhood through adolescence. In conclusion, BMI is larger in males in early childhood but larger in females in during adolescence. More female adolescents are at risk of obesity than males.
\end{abstract}

Keywords: adolescence, childhood, gender, obesity, overweight, Nigeria

\section{Introduction}

Overweight and obesity are serious health concerns for children and adolescents (Dock et al., 2005). Overweight and obese children are likely to stay obese into adulthood and more likely to develop chronic diseases at a younger age (Ogden et al., 2004). Obesity levels in children and adolescents have tripled over the past four decades (Dowd et al., 2001). The social and economic consequences of obesity may be as great as the health consequences (Gortmaker et al., 1993). Gender difference has been found for body mass index (BMI) among adolescents (Rosner et al., 2001). The findings in some studies (Cole et al., 2000; Maynard et al., 2001; NTFCO, 2008) on BMI suggest rising and falling nature of BMI from birth through adolescence. This pattern may reflect changes, overtime, in the prevalence of overweight and obesity derived from BMI with possible differential patterns between males and females.

A number of studies have examined overweight and obesity prevalence in samples of Nigerian adolescents (Akinpelu et al., 2008; Ben-Bassey et al., 2007; Olumakaiye, 2008; Akesode \& Ajibode, 2000; Ansa et al., 2008; Owa \& Adejuyigbe, 1983). Only Akesode \& Ajibode (2000) and Owa \& Adejuyigbe (1983) had, however, involved children but not pre-school children. None of these previous studies investigated the prevalence of overweight and obesity at different periods of childhood and adolescence or compared it between males and females. This study was carried out to determine the influence of gender on prevalence of overweight and obesity, and BMI, at different periods in childhood and adolescence among Nigerian schoolchildren. In this study, we defined childhood as the period from the age of two to the age of 10 whereas adolescence as 11 to 18 years.

\footnotetext{
*Correspondence: Fatai Maruf; E-mail: mafaad@yahoo.com
} 


\section{Materials and Methods}

This study was conducted in Nnewi in the tropical rain forest of Nigeria in 2009. As of 2006, Nnewi had an estimated population of 391,227 people according to Nigerian census (www.en.wikipedia.org./wiki/Nnewi). There were 44 pres-school/nursery/primary schools (23 private schools and 21 public schools), and 17 secondary schools (10 private schools and seven public schools). From a list obtained from the Local Educational Authority, a sample of 16 preschool/primary schools ( 8 private and 8 public) and 12 secondary schools (7 private and 5 public) was drawn by stratifying the schools into private and public schools and randomly selecting schools with probability proportional to size (Akinpelu et al., 2008). The draw was done separately for pre-school/primary and secondary schools.

A total of 9,014 children and adolescents (male=4,392; females $=4,622$ ), aged 2-18 years, were recruited into this study from the selected schools. This comprised 3,659 participants (male=1,835 female=1,854) from private schools and 5,355 participants (male=2,557; females $=2,798$ ) from public schools. Participants were categorized based on their ages into early childhood (2-6 years: male $=827$; female $=804$ ), late childhood ( $7-10$ years; male $=873$; female $=902$ ), early adolescence (11-14 yrs; male=1595; female=1795) and late adolescence (15-18 years; male=1097; female=1121). The students who had physical deformity that might make height measurement difficult were excluded.

Information on age and gender of the participants was collected from the school register. Weight was measured to the nearest 0.01 decimal place using a weighing scale (Hana, Model BR9011; $120 \times 0.01 \mathrm{~kg}$, China). Height was measured to the nearest 0.01 decimal place using a height meter. The participants were dressed as for weight measurement. The height meter was mounted on the wall and the participants stood erect, barefooted, and looked straight ahead. The measurement was taken on the meter against the vertex of the head (Maruf et al., 2012). The research assistants took the readings by bending over the scale with their eyes directly over it. The readings were taken when the pointer stabilized (Maruf et al., 2012). Body mass index (BMI) of the participants were calculated from their respective height and weight using the relation= Weight/Height ${ }^{2}$. From these BMI values, overweight and obesity were determined using the International Obesity Task Force (IOTF) cut-off points for overweight and obesity, by age and sex, for children 2-18 years (Cole et al., 2000). The IOTF cut-off points were determined from data from six large nationally representative cross-sectional growth studies. These points were defined to pass through BMI of 25 and $30 \mathrm{~kg} / \mathrm{m}^{2}$ at age 18 . They are suitable to compare prevalence rates of overweight and obesity in children.

\section{Data analysis}

Prevalence of overweight and obesity was presented using frequency and proportion based on IOTF cut-off points, by age and sex, for children 2-18 years. The significance of difference in prevalence of overweight and obesity between males and females was determined using Chisquare. Independent t-test was used to determine the significance of the differences in BMI between males and females at different stages of childhood and adolescence. SPSS 16.0 software was used for the statistical analysis.

\section{Ethical considerations}

Ethical approval for this study was given by the Ethics Committee of Nnamdi Azikiwe University Teaching Hospital, Nnewi. Prior to the day of data collection, written informed consent was obtained, through the participants, from their parents/guardians and each individual gave verbal assent to take part in the study. Visits to the schools were as agreed upon by the principals and teachers of the schools. At each of those visits, all the eligible students who had the consent of their parents/guardian were measured. Seventeen research assistants conducted this survey with 
the researchers. The research team was well-trained in the principles and methods involved in both weight and height measurements and recording of information.

\section{Results}

The overall prevalence of overweight in females (7.5\%) was higher than in males (4.7\%). Overall, the prevalence of overweight was $6.1 \%$. Overall, the prevalence of obesity was $0.8 \%$ (males $=0.7 \%$; females $=0.8 \%$ ). The prevalence of overweight and obesity for children was $7.8 \%$ and $1.5 \%$, respectively, and for adolescents it was $5.1 \%$ and $0.3 \%$, respectively. Other characteristics are shown in Table 1.

Table 1: Physical characteristics of the participants

\begin{tabular}{llll}
\hline Age group & Variable & \multicolumn{1}{c}{ Mean \pm SD } \\
\hline Child hood & Age (years) & $6.5 \pm 2.6$ & Female \\
& Height $(\mathrm{m})$ & $1.2 \pm 0.1$ & $6.5 \pm 2.6$ \\
& Weight $(\mathrm{kg})$ & $23.9 \pm 7.1$ & $1.2 \pm 0.1$ \\
& Body mass index $\left(\mathrm{kg} / \mathrm{m}^{2}\right)$ & $15.5 \pm 2.2$ & $23.8 \pm 7.3$ \\
Adolescence & $14.1 \pm 1.9$ & $15.4 \pm 2.4$ \\
& Age (years) & $1.6 \pm 0.1$ & $14.0 \pm 1.9$ \\
& Height $(\mathrm{m})$ & $45.2 \pm 10.6$ & $1.6 \pm 0.1$ \\
& Weight $(\mathrm{kg})$ & $18.5 \pm 2.3$ & $46.6 \pm 10.0$ \\
& Body mass index $\left(\mathrm{kg} / \mathrm{m}^{2}\right)$ & $19.5 \pm 2.8$ \\
\hline
\end{tabular}

For both sex, increases in prevalence of overweight were observed in childhood, whereas during adolescence, the prevalence of overweight tended to decrease in males but increase in females. However, prevalence of obesity tended to decrease with age in males and females from childhood through adolescence (Table 2). Females had higher prevalence of overweight $(\mathrm{P}<0.05)$ than males at only age groups 11-14 years and 15-18 years. However, there was no gender difference in the prevalence of obesity from childhood through adolescence (Table 2 ).

Table 2: Prevalence of overweight and obesity in male and female participants by age group

\begin{tabular}{lllllll}
\hline Variable & Age group & No. & Male (\%) & Female (\%) & $\chi^{2}$ & P-value \\
\hline Overweight & $2-6$ & 94 & 5.3 & 6.2 & 0.38 & 0.61 \\
& $7-10$ & 173 & 8.5 & 11.0 & 3.61 & 0.06 \\
& $11-14$ & 173 & 3.5 & 6.5 & 21.51 & $<0.001$ \\
& $15-18$ & 112 & 2.9 & 7.1 & 20.57 & $<0.001$ \\
Obese & Overall & 552 & 4.7 & 7.5 & 35.51 & $<0.001$ \\
& $2-6$ & 38 & 2.5 & 2.1 & 0.42 & 0.64 \\
& $7-10$ & 14 & 0.9 & 0.7 & 0.29 & 0.79 \\
& $11-14$ & 12 & 0.2 & 0.5 & 3.00 & 0.14 \\
& $15-18$ & 7 & 0.0 & 0.6 & $*$ & $*$ \\
& Overall & 71 & 0.7 & 0.8 & 0.69 & 0.48 \\
\hline
\end{tabular}

* $=$ could not be performed using $\chi^{2}$

The BMI of males was higher $(P<0.05)$ than that of females at age groups $2-6$ years. The females, however, had higher BMI $(P<0.05)$ than males in age groups 11-14 years and 15-18 years (Table 3 ). 
Table 3: Comparison of body mass index of male and female participants by age group

\begin{tabular}{llll}
\hline Age group in years $(\mathrm{N})$ & $\begin{array}{l}\text { Male } \\
\text { Mean } \pm \text { SD }\end{array}$ & $\begin{array}{l}\text { Female } \\
\text { Mean } \pm \text { SD }\end{array}$ & P-value \\
\hline $2-6(1631)$ & $14.9 \pm 2.2$ & $14.7 \pm 2.3$ & 0.02 \\
$7-10(1775)$ & $16.1 \pm 2.1$ & $16.1 \pm 2.2$. & 0.93 \\
$11-14(3390)$ & $17.8 \pm 2.1$ & $18.6 \pm 2.6$ & $<0.001$ \\
$15-18(2218)$ & $19.5 \pm 2.2$ & $20.9 \pm 2.5$ & $<0.001$ \\
\hline
\end{tabular}

\section{Discussion}

This study showed that males had a higher BMI value during early childhood whereas the reverse occurred throughout adolescence. In addition, females had significantly higher prevalence of overweight than males throughout adolescence. However, the prevalence of obesity for males and females were not significantly different from childhood through adolescence. The findings of gender differences in BMI in early childhood and throughout adolescence may be attributed to the growth spurt and development of secondary sexual characteristics of each sex corresponding to age range at which they have greater heights. The findings of higher BMI in females during adolescence conform to those of a previous study by Maynard et al. (2001). According to Rosenfeld (2004), both male and female humans experience pubertal growth spurts and are not sexually dimorphic in adult stature. This pubertal growth spurt occurs during adolescence and serves to prepare the child for adulthood. This means that the organs and characteristics required for certain roles in adulthood are developed during this period, and because the reproductive patterns of human have evolved away from the male-dominated social structure, the larger male size than the female no longer confers a reproductive advantage (Rosenfeld, 2004). The relatively larger female size might have evolved to support the birth of offspring in adulthood (Rosenfeld, 2004). This may explain the reason why females were found, in this study, to be of higher BMI during adolescence.

The findings for the influence of gender on the overall prevalence of overweight and obesity in the current study, contradict the findings in a previous study by Krassas et al. (2004). In the Krassas et al. (2004) study, the analysis of difference was carried out for the whole childhood and adolescence periods as against stage-by-stage analyses in the present study. Furthermore, the differences in these findings might be due to differential genetic, environmental and sociocultural factors between the two populations. Furthermore, the differences in patterns of prevalence between males and females in childhood and adolescence in this study could be due to differences in physiological processes between the two sexes in those phases of life.

There was a decreasing trend, from early childhood through adolescence, in the prevalence of obesity in males and in females. Furthermore, the finding for the prevalence of overweight in males and females, during adolescence, is partly supported by a study by Zalilah et al., (2006) which found that as age increased, the prevalence of overweight among rural Malaysian adolescents decreased. Zephier et al. (1999) however, found the prevalence of obesity in males increasing with age among American Indian school children and adolescents, contrary to findings in this study. The break in the decreasing pattern of prevalence of overweight in age 7-10 years, for males in the present study, may suggest that even when BMI increases from age 6 as reported by Cole et al (2000), it probably is not enough to beat the overweight and obesity cutoff points for adolescent ages to sustain the increasing trend till age 18 years.

The prevalence of overweight and obesity among children and adolescents in our study was found to be well below that for the Greek and Turkish children (Krassas et al., 2004; Oner et al., 2004) as well as in some previous Nigerian studies (Akesode \& Ajibode, 2000; Akinpelu et al., 2008; Musa et al., 2012). The finding of lower prevalence in the present study than in the previous studies might be due to involvement of pre-school children in this study. However, findings of 
decreasing trends of obesity from childhood through adolescence do not make this argument plausible. The previous Nigerian studies were carried out in the South-Western (Akesode \& Ajibode, 2000; Akinpelu et al., 2008) and North-Central (Musa et al., 2012) Nigeria as opposed to South-Eastern base of the present study. The differences in geographical locations of the populations of these studies with distinct genetic, environmental and socio-cultural backgrounds could be contributory.

The strength of these data lies in the sample size and random selection of schools for data collection. In interpreting the findings from this study, however, certain limitations need to be considered. No data on other correlates of BMI such as physical activity level, dietary pattern and socio-economic backgrounds were collected. These variables may confound the findings for gender differences and ought to have been adjusted out. At any rate, this study further extended the previous ones by including children in pre-nursery, nursery and kindergarten. Future study of this nature is awaited with these limitations taken into consideration. In conclusion, there was a decreasing trend, from early childhood through adolescence, in the prevalence of overweight and obesity in males, and in the prevalence of only obesity in females. Body mass index is larger in males in early childhood but larger in females during adolescence. More females are at risk of obesity than males from late childhood through adolescence whereas, no gender difference was observed in the prevalence of obesity from childhood through adolescence.

\section{References}

Akesode, F.A. \& Ajibode, H.A. (2000) Prevalence of obesity among Nigerian schoolchildren. Social Science \& Medicine 17,107-111.

Akinpelu, A.O., Oyewole, O.O. \& Oritogun, K.S. (2008) Overweight and obesity: does it occur in Nigerian adolescents in an urban community? International Journal of Biomedical and Health Sciences 4 (e-publication).

Ansa, V.O., Anah, M.U. \& Ndifon, W.O. (2008) Soft drink consumption and overweight/obesity among Nigerian adolescents. CVD Prevention and Control 3, 191-196.

Ben-Bassey, U.P., Oduwole, A.O., Ogundipe, O.O. (2007) Prevalence of Overweight and obesity in Eti-osa LGA, Lagos, Nigeria. Obesity Review 8,475-479.

Cole, T.J., Bellizzi, M.C., Flegal, M. \& Dietz, W. (2000) Establishing a standard definition for child overweight and obesity worldwide: international survey. British Medical Journal 320, 1-6.

Doak, C.M., Vischer, T.L.S., Renders, C.M. \& Seidell, J.C. (2005) The prevention of overweight and obesity in children and adolescents: a review of interventions and programmes. Obesity Reviews 7,111-136.

Dowda, M., Ainsworth, B.E., Addy, C.L., Saunders, R. \& Riner, W. (2001) Environmental influences, physical activity, and weight status in 8- to 16-year-olds. Archive of Paediatric and Adolescent Medicine 155, 711-717.

Gortmaker, S.L., Must, A., Perrin, J.M., Sobol, A.M. \& Dietz, W.H. (1993) Social and economic consequences of overweight in adolescence and young adulthood. New England Journal of Medicine 329, 1008-1012

Krassas, G.E., Tsametis, C., Baleki, V., Constantinidis, T., Kurtoglu, S. \& Kelestimur, F. (2004) Prevalence of overweight and obesity among children and adolescents in ThessalonikiGreece and Kayserri-Turkey. Journal of Pediatric Endocrinology Review 11 (Suppl 3), 460464.

Maruf F.A., Aderonke, O.A, Aronu, U.C. \& Akinpelu, A.O. (2012) Socio-economic differentials in height, weight and body mass index of school adolescent in Nnewi, South-Eastern Nigeria. Internet Journal of Biological Anthropology 4(2) e-pub.

Maynard, L.M., Wisemandle, W., Roche, A.F., Chumlea, W.C., Guo, S.S. \& Siervogel, R.M. (2001) Childhood body composition in relation to body mass index. Paediatrics 107, 344-350. 
Musa, I.D., Toriola, A.L., Monyeki, M.A., Lawal, B. (2012) Prevalence of childhood and adolescent overweight and obesity in Benue State, Nigeria. Tropical Medicine and International Health $17,1369-1375$.

NTFCO (2008) National Task Force on Childhood Obesity, National Centre for Women's and Children's Health. 2008 National Epidemiological Survey on Childhood Obesity. Zhonghua er ke za zhi. Chinese Journal of Pediatrics 46, 179-84.

Ogden, C.L., Fryar, C.D., Carroll, M.D. \& Flegal, K.M. (2004) Mean body weight, height, and body mass index, United States 1960-2002. Advanced data from vital and health statistics; no 347. Hyattsville, Maryland: National Centre for Health Statistics. www.cdc.gov/nchs/data/ad/ad347.pdf accessed on 17/11/2011

Olumakaiye, M.F. (2008) Prevalence of underweight: a matter of concerns among adolescents in Osun State, Nigeria. Pakistan Journal of Nutrition 7, 503-508.

Oner, N., Vatansever, U., Sari, A., Ekuklu, E., Güzel, A., Karasalihoğlu, S. \& Boris, N.W. (2004) Prevalence of underweight, overweight and obesity in Turkish adolescents. Swiss Medical Weekly 134, 529-533.

Owa, J.A. \& Adejuyigbe, O. (1983) Fat mass percentage, body mass index and upper arm circumference in a healthy population of Nigerian children. Journal of Tropical Paediatrics 43, $13-19$.

Rosenfeld, E.G. (2004) Gender difference in height: an evolutionary perspective. Journal of Paediatric Endocrinology and Metabolism 17, 1267-1271.

Rosner, B., Prineas, R., Loggie, J. \& Daniels, S.R. (2001) Percentiles for body mass index in US children 5 to 17 years of age. International Journal of Obesity-Related Metabolic Disorders $25,1517-1524$

Zalilah, M.S., Mirnalini, K., Khor, G.L., Merlin, A., Bahaman, A.S. \& Norimah, K. (2006) Estimates and distribution of body mass index in a sample of Malaysian adolescents. Medical Journal of Malaysia 61, 48-58.

Zephier, E., Himes, J.H. \& Story, M. (1999) Prevalence of overweight and obesity in American Indian school children and adolescents in the Aberdeen area: a population study. International Journal of Related Metabolic Disorders 23 (Suppl 2), S28-30. 